\title{
Nous avons lu pour vous
}

\section{Du bon usage des plantes qui soignent}

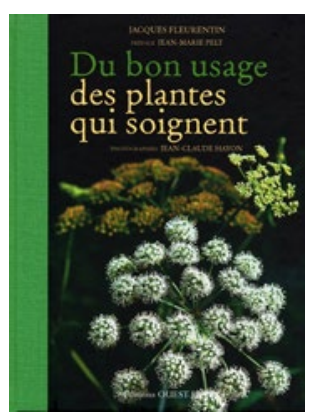

L'ouvrage de Jacques Fleurentin s'est enrichi dans cette réédition de trente pages supplémentaires d'actualités sur les propriétés des plantes, de la présentation de six nouvelles plantes et de la réactualisation de la réglementation européenne.

Jacques Fleurentin présente 155 plantes classées en dix chapitres, en fonction de leur indication thérapeutique principale. Ainsi, les plantes de l'anxiété, du tonus, de la douleur, des reins, du foie, du système digestif, de la circulation sanguine, des poumons, des troubles hormonaux et de la peau sont présentées dans un langage clair, précisant notamment les posologies à respecter.

Un index thérapeutique et un glossaire permettent de mettre à profit de façon simple ce précieux savoir.

$D u$ bon usage des plantes qui soignent, réédition revue et augmentée des Tomes 1 et 2 "Les plantes qui nous soignent, traditions et thérapeutique", Jacques Fleurentin, préfacé par Jean-Marie Pelt, Éditions Ouest-France, 518 pages, $25 €$ (+ frais de port), disponible également auprès de la Société française d'ethnopharmacologie, 1, rue des Récollets, F-57ooo Metz, Tél. : 0387748889 ; email : sfe-see@sfr.fr

\section{La santé naturelle avec les huiles essentielles}

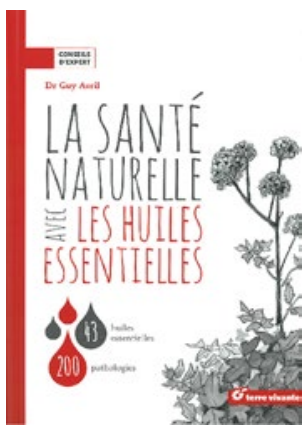

Les huiles essentielles, obtenues principalement par distillation de plantes, sont généralement anti-infectieuses et anti-inflammatoires, en plus de leurs puissantes propriétes spécifiques. Employées a bon escient, elles corrigent les principaux déséquilibres impliqués dans les maladies.

Cet ouvrage présente :

- 43 huiles essentielles avec leurs propriétés, indications, contreindications... (lavande, fenouil, ylang-ylang...);

- 200 pathologies à soigner dans tous les domaines (maladies de la peau, digestives, ORL, cardio-vasculaires...) ;

- 200 formules de soins : certaines, simples, sont réalisables par soi-même. D’autres, plus complexes, seront préparées par un pharmacien compétent.

La santé naturelle avec les huiles essentielles, Dr Guy Avril (médecin généraliste), Éditions Terre vivante, Collection

"Conseils d'expert ", 240 pages, $19 €$ 